\title{
An Evaluation on the Implementation Effect of the National Standard - Norm of Water Intake-Part 1: Fossil Fired Power Production (GB/T18916.1-2012)
}

\author{
Cai Rong ${ }^{1}$, Bai Xue ${ }^{1 *}$, Hu Mengting ${ }^{1}$, Zhang Yubo ${ }^{1}$, Zhang Lijia ${ }^{1}$, Zhang jiawei ${ }^{2}$ \\ ${ }^{1}$ Resource and Environmental Branch, China National Institute of Standardization, Haidian District, Beijing, 100191, China \\ ${ }^{2}$ National Academy of Forestry and Grassland Administration, Beijing,100000, China
}

\begin{abstract}
The evaluation on the implementation effect of the standard not only constitutes an important basis for promoting the implementation and the quality of the standard, but also provides an important technical basis for implementing national water conservation actions and achieving the dual control targets for water consumption and intensity. This article analyzes and evaluates the implementation effect of the National Standard GB/T18916.1-2012 Norm of Water Intake-Part 1: Fossil Fired Power Production from three aspects including the Standard's technical indexes, implementation effect and implementation benefits, and provides a foundation and reference to study and conduct evaluations on the implementation effect of the national standard for the norm of water intake.
\end{abstract}

\section{Introduction}

With the rapidly development of society and economic, the shortage of water resources is increasingly serious ${ }^{[1]}$, which become the bottleneck of the sustainable development of economic in China ${ }^{[2]}$. The norm of water intake for industrial products is one of the main indicators for the assessment of water efficiency and water conservation level of each industry and enterprise ${ }^{[3]}$. It is also a vital control indicator of water supply for the enterprises' and the basic of water management and distribution by enterprises ${ }^{[4]}$. In order to promote the development of a feedback mechanism for the implementation status and effect of standards, which could respond to requirement of the State Council in the Plan for Deepening the Reform of Standardization Work ${ }^{[5]}$ to "conduct evaluations on the implementation effect of a standard and establish a mandatory statistical analysis and reporting mechanism for the implementation of national standards", and improve the alignment between standard formulation and the implementation effect, it is necessary to carry out evaluations on the implementation effect of the national standard for the norm of water intake in the fossil fired power production industry as a typical water-intensive industry, since it is significant for continuously promoting the formulation and revision of the standard for the norm of water intake in this industry and for a more effective implementation and application of the standard.

\section{Analysis of current situation}

\subsection{The current situation of fossil fired power production}

Fossil fired power plants play an important role in development of China ${ }^{[6]}$. At present, more than $80 \%$ of the country's power plants are fossil fired power plants, and most of these enterprises are water-intensive [7]. However, the circulating water system still could be improved ${ }^{[8]}$. According to the research of current situation, it is obvious that the quantity of fossil fired power generation has shown a continuous upward trend. However, the total water consumption of fossil fired power generation in China was $4.54 \times 10^{9}$ tons in 2000 , and reached a peak of $9.13 \times 10^{9}$ tons in 2011. In 2017, the fossil fired power generation decreased by $37.7 \%$ to $5.69 \times 10^{9}$ tons (See Figure 1).

\footnotetext{
*Corresponding Author: baixue@cnis.ac.cn
} 


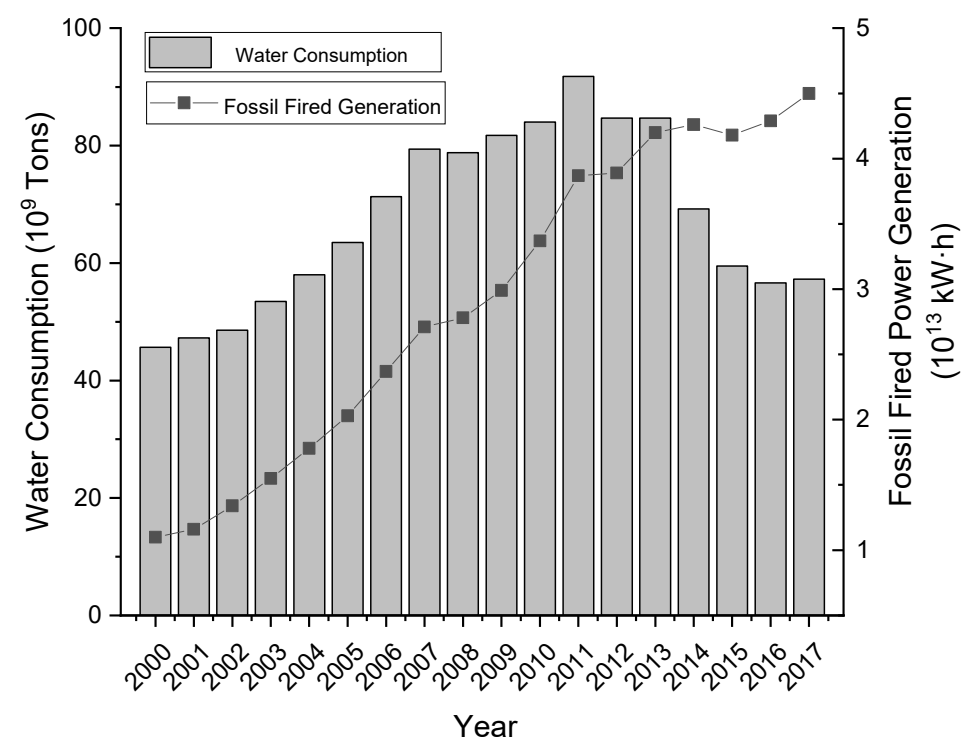

Fig 1. Changes of fossil fired power generation and water consumption in China (2000-2017)

Analysis the data of 2000 and 2017, the trend showed that the fossil fired power generation increased by 3.1 times, at the same time, the water consumption of the industry just increased by $25 \%$. The result pointed out that the water consumption for unit power generation quantity is $1.25 \mathrm{~kg} / \mathrm{kW} \cdot \mathrm{h}$, which decreased by $69.5 \%$ with the water consumption in 2000 (See Figure 2). Consequently, the effect of water conservation of fossil fired power generation was remarkable.

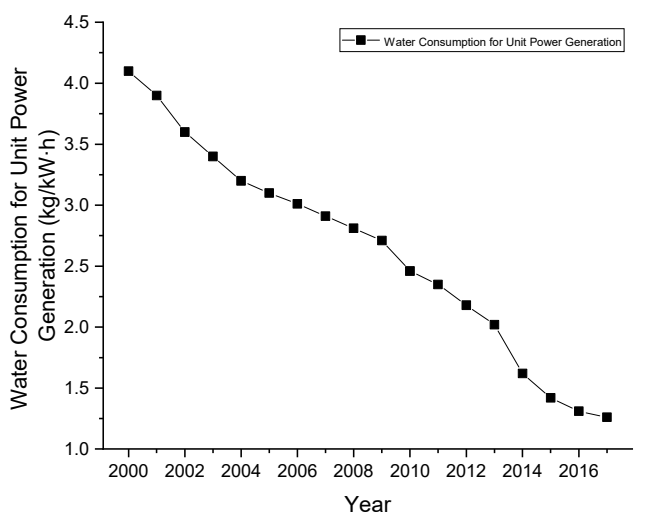

Fig 2. The water consumption for unit power generation (2000-2017)

\subsection{Introduction of the standard GB/T18916.1- 2012}

As the first part of the national standard for the norm of water intake, National Standard GB/T18916.1-2012 Norm of Water Intake-Part 1: Fossil Fired Power Production ${ }^{[9]}$ was published on June 29, 2012 and took effect as of January 1, 2013, replacing GB/T18916.1-2002. The standard specifies the terms and definitions, calculation method, and the norm of water intake for fossil fired power production, and is applicable to the management of water intake during the production and design process of fossil fired power production enterprises in electric power industry. The standard has improved the national standard system for the norm of water intake, and effectively supported the implementation of several policies in China, such as the access policy for water consumption and water conservation in water-intensive industries, the most stringent water management mechanism, the National Water Conservation Action, the Water Consumption and Intensity dual-control, which greatly promoted the improvement of water conservation management and technologies in industries and enterprises ${ }^{[10]}$.

\section{Evaluation on the implementation effect of the standard}

There are a large number studies on the evaluation of the implementation of standards abroad. In 1997, the study on the economic benefits of standardization in Germany, Austria and Switzerland organized by the German Ministry of economy and technology and the German Society for Standardization (DIN), which shows the result 
that standards contributed substantially to the economic growth in the second half of the last century ${ }^{[11]}$. BSI and CBI have organized studies about the contribution of standardization to long-term productivity growth in British, which pointed out there is a positive correlation between standard stock and labor productivity [12, 13]. Besides, the other studies also identified the implementation of standards has a positive role in promoting the economy ${ }^{[14,15]}$.

The evaluation and study on the implementation effect of the standard for water conservation could help standardization personnel understand the benefits of the standardization work ${ }^{[16]}$, and at the same time identify weaknesses and promote the improvement of water conservation technologies and management ${ }^{[17]}$. The evaluation on the implementation effect of the standard often involves multiple factors and indicators, which is a comprehensive analysis with the interaction of multiple factors ${ }^{[18]}$. The shortcomings and gaps of the evaluated object may be identified through the comprehensive evaluation, so that improvement measures may be adopted timely or future work may be carried out accordingly.

For the evaluation on the implementation effect of the National Standard Norm of Water Intake-Part 1: Fossil Fired Power Production, this paper mainly uses questionnaires to collect data from two aspects, the implementation of the Standard (GB/T18916.1-2012), water intake and consumption in the industry, which covers 268 fossil fired power plants in 28 provinces and cities. The main contents of the survey are shown in Table 1.

Table1. Main Contents of the Survey

\subsection{Evaluation of the technical indexes}

\subsubsection{Evaluation of the applicability}

The evaluation of the applicability of the standard mainly analyzes the current industry status and the industry status at the time of standard formulation to decide whether the goal of improving backward production capacity has been achieved, and to determine the degree of consistency between the norm indexes and the market development needs ${ }^{[19,20]}$. Through an analysis of the survey results, it is obvious that the water intake of the three types of cooling mode which including recirculating cooling, once-through cooling, and air cooling, with the unit rated capacity respectively under $300 \mathrm{MW}$, at $300 \mathrm{MW}$, and at or above $600 \mathrm{MW}$, and compare them with the norm indexes of water intake in GB/T18916 .1-2012 (see Table 2).

Table2. A Comparison between the Current Water Intake in the Fossil Fired Power Production Industry and the Norm Indexes of Water Intake in GB/T18916.1-2012

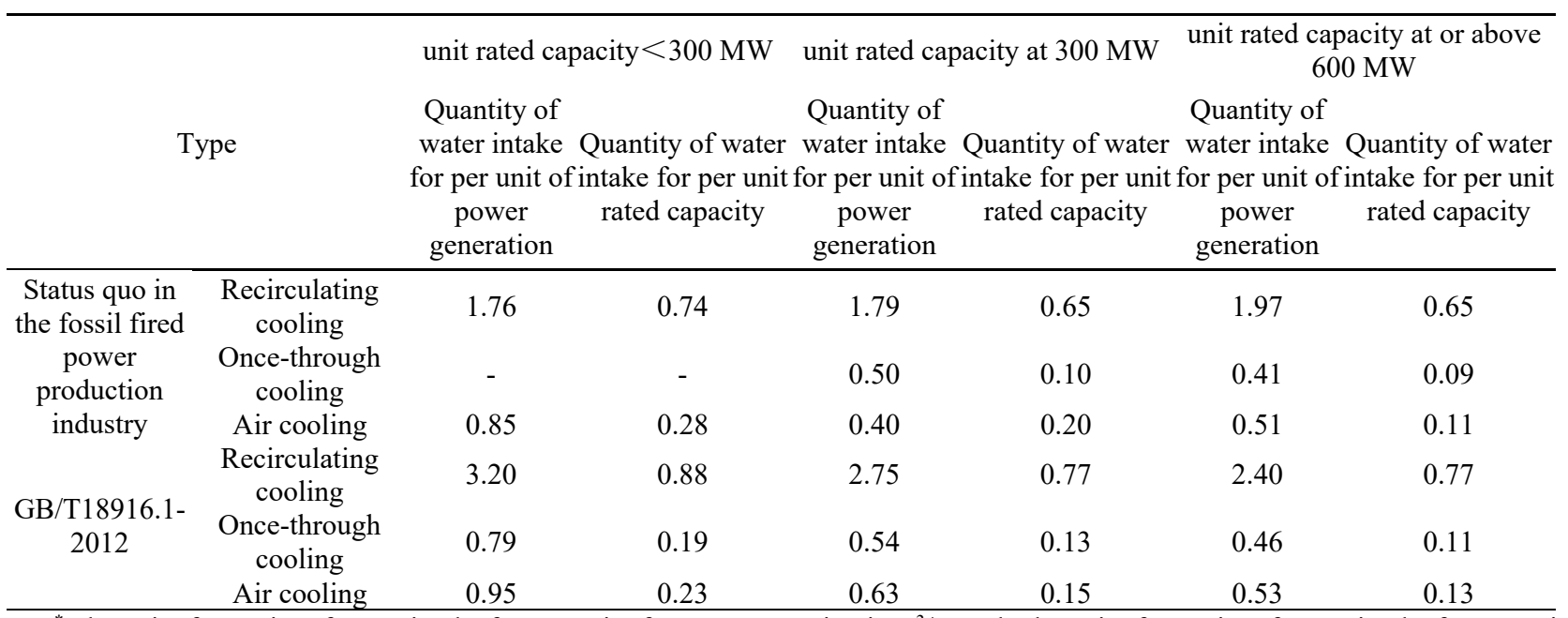

Note : the unit of quantity of water intake for per unit of power generation is $\mathrm{m}^{3} / \mathrm{MW} \cdot \mathrm{h}$, the unit of quantity of water intake for per unit rated capacity is $\mathrm{m}^{3} /(\mathrm{GW} \cdot \mathrm{S})$.

(1) Whether the goal of improving backward production capacity has been achieved
In the formulation of the standard, the principle for determining the norm indexes was to ensure that more 
than $60 \%$ of the generating sets at that time could achieve such indexes ${ }^{[21]}$. Based on the unit rated capacity of fossil fired power production sets at that time, about 300 million kilowatts of generating sets could not meet the requirements of the norm indexes. According to an analysis of the current water intake in the fossil fired power production industry, $92 \%$ of the generating sets with recirculating cooling, $75 \%$ of the sets with oncethrough cooling, and $76 \%$ of the sets with air cooling can meet the requirements of the norm indexes in the standard, that is, on average, $81 \%$ of the sets can meet the requirements. Based on the current unit rated capacity of fossil fired power production sets, after the implementation of the standard, about 186 million kilowatts of generating sets could not meet the requirements. Therefore, the implementation of the standard has at least promoted the index reaching of 114 million kilowatts of backward production capacity, with an index reaching proportion of $15 \%$.

(2) The consistency between the norm indexes and market development demand

According to a comparison of the degree of consistency between the norm indexes and the market development demand, the norm indexes are lower than the average level of the surveyed enterprises. However, $8 \%$ of the sets with recirculating cooling, $25 \%$ of the sets with once-through cooling, and $24 \%$ of the sets with air cooling in the surveyed enterprises could not reach the requirements for the quantity of water intake for per unit of power generation in the standard, and $15 \%$ of the sets with recirculating cooling, $25 \%$ of the sets with oncethrough cooling, and $33 \%$ of the sets with air cooling could not reach the requirements for the quantity of water intake for unit rated capacity in the standard. It shows that the norm indexes are basically consistent with the current development and demand of the industry.

\subsubsection{Evaluation of the advancement}

Developed countries have carried out lots of work on the laws, regulations, technical standards, product quality, testing, and system management which related to water conservation evaluation ${ }^{[22]}$. For example, countries such as the United States, Australia, and Japan have implemented national water resources standardization projects to test and manage water resources, established evaluation systems, and strengthened water management, which achieving significant water conservation and emission reduction benefits ${ }^{[23]}$. However, there is no standard for the norm of water intake and consumption in in foreign countries.

With the average water consumption for power generation in 2008 as an example, the average quantity of water intake for unit power generation quantity by fossil fired power production sets in China was 1.11 times that of the average level of advanced countries, which was 1.57 times that of the United States, and 2.24 times that of South Africa (Table 3). Through decades of improvement in water conservation technologies, the current quantity of water intake for unit power generation quantity by fossil fired power production sets in China is $1.25 \mathrm{~m}^{3} /(\mathrm{MW} \cdot \mathrm{h})$, which is about $55 \%$ lower than that in 2008 (Table 3) ${ }^{24-}$ 26].

Table3. A Comparison of the Average Water Intake between Domestic and Foreign Power Plants (2008)

\begin{tabular}{ccc}
\hline Evaluated target & $\begin{array}{c}\text { Water intake per unit of power } \\
\text { generation } / \mathrm{kg} / \mathrm{kW} \cdot \mathrm{h}\end{array}$ & $\begin{array}{c}\text { Water intake per unit of installed } \\
\text { capacity } / \mathrm{t} / \mathrm{GM} \cdot \mathrm{S}\end{array}$ \\
\hline Average value in China & 2.80 & 0.58 \\
Average value in advanced countries & 2.52 & 0.700 \\
Average value in the United States & 1.78 & 0.490 \\
Average value in South Africa & $1.25(0.2$ for air cooling $)$ & $0.347(0.056$ for air cooling $)$ \\
$\begin{array}{c}\text { Average value in power plants with } \\
\text { recirculating cooling in Germany }\end{array}$ & $1.8-2.4$ & 0.500 \\
$\begin{array}{c}\text { Reuther West Power Plant of Germany } \\
\text { (1,000 MW) } \\
\text { Bay Power Plant of Canada }\end{array}$ & & \\
& & 0.544 \\
\hline
\end{tabular}

Based on the comparison of the data and consultancy of industry experts, the results shows that the technical indexes in GB/T18916.1-2012 are currently at the international leading level, basically equivalent to the average level of advanced countries. However, it could be seen from the comparison that the quantity of water intake for unit power generation quantity in the standard is still 1.35 times that of South Africa, especially the value of air cooling sets is 3.5 times. Besides, the quantity of water intake for unit rated capacity in the standard is 1.37 times that of South Africa, especially the value of air cooling sets is 3.04 times. Therefore, there still has the large gap and enormous potential for water conservation in China.

\subsubsection{Evaluation of the reconciliation}

The evaluation of the reconciliation of the standard mainly refers to the comparison with the domestic cleaner production evaluation index systems and standards, local standards for the norm of water consumption, and other documents which related to the norm indexes of water intake, with a purpose to determine the reconciliation of the technical indexes.

(1) Comparison of key technical indexes with relevant national, industry and local standards

Through a search of existing national, industry and 
local standards, we have found one national standard to be related to GB/T18916.1-2012, that is, Water Saving Enterprises-Fossil Fired Plant [27], in which the norm index is broader than the quantity of water intake for unit rated capacity and stringent than the quantity of water intake for unit power generation quantity. Besides, the sub-paragraph 7.2.1 of the industry standard Water Saving Guideline for Fossil fired power production Plant [28] stipulates that "the water intake by fossil fired power production plants shall meet the requirements of GB/T18916.1". In addition, a total of 30 provinces and cities across the country have formulated water consumption norms for fossil fired power production, of which 4 local norm standards have a lower requirement on norm indexes, 16 local norm standards have consistent with GB/T18916. However, these has 10 local standards could not be compared due to the different classification scales.

(2) Degree of reconciliation with relevant national documents

In recently years, the government has published some policy to specifics the water intake and consumption in fossil fired power production (See Table 4).

Table4. Adoption of the Standard by the Administrative Sector

\begin{tabular}{cc}
\hline Department & Policy \\
\hline Ministry of Water Resources of the People's & $\begin{array}{c}\text { Opinions on Conducting Water Resources Demonstrations for } \\
\text { the Development and Planning of Large Coal Power Bases }\end{array}$ \\
National Development and Reform & Evaluation Index System for Cleaner Production in the Power \\
Commission, Ministry of Ecology and & (Coal Fired Power Generation Enterprises) Industry \\
Environment, and Ministry of Industry and \\
Information Technology of the People's \\
Republic of China
\end{tabular}$\quad \begin{gathered}\text { National Development and Reform } \\
\text { Commission, Ministry of Water Resources, and } \\
\text { Ministry of Housing and Urban-Rural } \\
\text { Development of the People's Republic of } \\
\text { China }\end{gathered}$

Through comparison, it is obvious that the indexes prescribed in the three national documents are all higher than the index requirements in the Norm of Water IntakePart 1: Fossil Fired Power Production (GB/T18916.12012).

\subsection{Evaluation of implementation effect}

\subsubsection{Evaluation of the promotion}

The evaluation of the promotion mainly evaluates the three aspects: the training of the standard, the citation of the standard in scientific papers, and the spread of the derivative materials of the standard ${ }^{[20]}$. From 2013 to 2017 , the Ministry of Water Resources, the Ministry of Industry and Information Technology, the National Water Conservation Standardization Technical Committee (SAC/TC 442) and other organizations organized a total of 22 related training sessions for the publicity of the Standard, with a total of more than 2,000 people trained.
A total of 4 scientific articles cited the Standard, and downloads reached 154 times. In addition, the main derivative material of the Standard, Water Intake Standardization Theories, Methods and Their Application, was officially published in March 2015. This book provides a technical basis for improving the theoretical system for compiling China's standard for the norm of water intake, and for China's water consumption cap control and quota allocation mechanism. It was printed for the first time in April 2015, and its sales volume reached about 1,000 copies.

\subsubsection{Evaluation of the implementation}

Standard implementation is mainly evaluated from three aspects: administrative sector, enterprises, and third-party institutions. Since publication, the standard has been adopted by government departments in 6 documents, and by river basin agencies and local authorities in 3 documents, as shown in Table 5.

Table5. Adoption of the Standard by the Administrative Sector

\begin{tabular}{|c|c|}
\hline Sector & Main content \\
\hline $\begin{array}{l}\text { Gov } \\
\text { dep }\end{array}$ & $\begin{array}{l}12^{\text {th }} \text { Five-Year Plan for Building a Water Conservation-Minded Society (Ministry of Water } \\
\text { Resources, January 2012) } \\
\text { Notice of the State Council on Issuing the Action Plan for Prevention and Control of Water } \\
\text { Pollution (GF [2015] No. 17) } \\
\text { Action Plan for Water Conservation Nationwide (FGHZ [2016] No. 2259) } \\
\text { Action Plan for the Dual Control of Total Water Consumption and Intensity during the 13 }{ }^{\text {th }} \text { Five- } \\
\text { Year Plan Period (SZY [2016] No. 379) } \\
13^{\text {th }} \text { Five-Year Plan for Building a Water Conservation-Minded Society (FGHZ [2017] No. 128) } \\
\text { Guiding Opinions of the National Development and Reform Commission and the Ministry of } \\
\text { Housing and Urban-Rural Development on Accelerating the Establishment and Improvement of } \\
\text { a Progressive Pricing Mechanism for Over-Quota Non-Residential Water Consumption (FGJG } \\
{[2017] \text { No. 1792) }}\end{array}$ \\
\hline
\end{tabular}




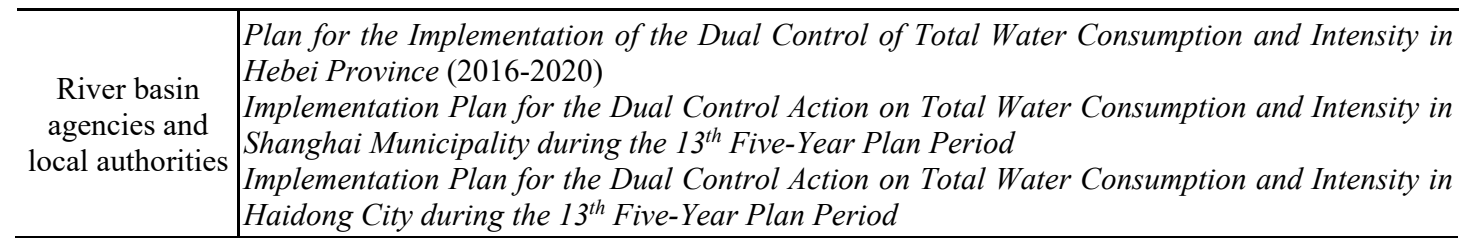

The evaluation on the standard implementation of enterprises, which is based on the 268 enterprises surveys. Among the surveyed enterprises, 259 of them were aware of the standard, accounting for $97 \% ; 243$ mastered the main content, accounting for $91 \% ; 241$ incorporated it in their water conservation management system, accounting for $90 \%$. It is clear that this standard is well known around the China, has the great mastered and implemented by the enterprises.

The standard was used as a guide in the water-saving transformation and the production of fossil fired power production plants. A variety of water-saving activities were carried out and great water-saving and economic benefits were achieved ${ }^{[29]}$. According to industry statistics, the average water intake per unit of power generation of the entire industry in 2017 was $1.25 \mathrm{~m}^{3} / \mathrm{MW} \cdot \mathrm{h}$, which was about $41.9 \%$ lower than that in 2012 .

Regarding the adoption of the standard, third-party institutions stipulated in the industry standard that "the water intake could be comprehensively evaluated based on GB/T18916.1 and the quantity of water intake for unit rated capacity of power plants" ${ }^{[30]}$. At the same time, during a water balance test on a fossil fired power production plant which taken by Guangzhou Institute of Energy Testing, has pointed out the existing problems, water conservation potential, water saving measures and expected results based on the standard ${ }^{[31]}$.

\subsubsection{Evaluation of the citation}

Since the publication and implementation of the standard, it has been quoted in the Regulations for the Administration of Water Intake Permits and Collection of Water Fees (State Council Order, No. 460). There were mainly 5 national standards that cited the standard as a normative reference, involving design specifications, water saving enterprises evaluation, water consumption management guideline, water consumption audits, and water conservation assessment. A total of 4 industry standards quoted the standard. In addition, a total of 16 local standards cited the standard and adopted the requirement of norm indexes. However, the standard has not been cited in international standards.

\subsection{Evaluation of the implementation benefits}

\subsubsection{Evaluation of the economic benefits}

The norm of water intake for the fossil fired power production industry is an important basis for measuring the water conservation level, and also a key measure to improve water efficiency in industry ${ }^{[32,33]}$. According to an analysis of the survey results, in 2017, the water intake for unit power generation quantity in the entire industry was $1.25 \mathrm{~m}^{3} / \mathrm{MW} \cdot \mathrm{h}$, which was about $41.9 \%$ lower than that in 2012. The quantity of water conservation accounted for about $10.07 \%$ of annual water intake.

\subsubsection{Evaluation of the social benefits}

The social benefits are mainly evaluated from the aspect of corporate social responsibility ${ }^{[34]}$, such as participating in the evaluation for water efficiency leaders and watersaving enterprises, which organized by the National Development and Reform Commission, the Ministry of Water Resources, and the Ministry of Industry and Information Technology. Besides, the enterprises of the fossil fired power production industry could also participate in the creation of water-saving entities and water conservation standard demonstrations and pilots organized by local authorities.

This standard is the important part of the norm of water intake standard system in China, which is the main basis for implementing planned water consumption and water permit mechanism, and take the significant support for conducting water resource demonstrations. It plays an essential role in the water conservation management and technological innovation of enterprises ${ }^{[35]}$. In addition, it is an important support for the establishment and improvement of water conservation standard system in China, and other Chinese polies. However, during the implementation of the standard, there is no enterprise participated in the relevant selection programs.

\subsubsection{Evaluation of the ecological benefits}

The ecological benefits are mainly evaluated in terms of the reduction of waste water discharge by enterprises after the implementation of the norm standard.

The trend of discharge of waste water and the quantity of fossil fired power generation ${ }^{[36]}$ was shown in Figure 3. According to calculations, the discharge of waste water nationwide by the fossil fired power production industry decreased by $49 \%$ from 2012 to 2017 , which from $5.49 \times 10^{9}$ tons decreased to $2.80 \times 10^{9}$ tons. It means that the annual average reduction rate is $9.8 \%$.

Based on a statistical analysis, the discharge of waste water for unit power generation shown the obvious decrease trend from 2012 to 2017, which was shown in Figure 4 . Take the survey result into consideration, there are $28 \%$ of the enterprises shows the significant decreases in waste water discharge, and $18.7 \%$ of the enterprises achieved zero discharge of waste water, after the implementation of the Norm of Water Intake-Part 1: Fossil Fired Power Production by fossil fired power production generation enterprises. 


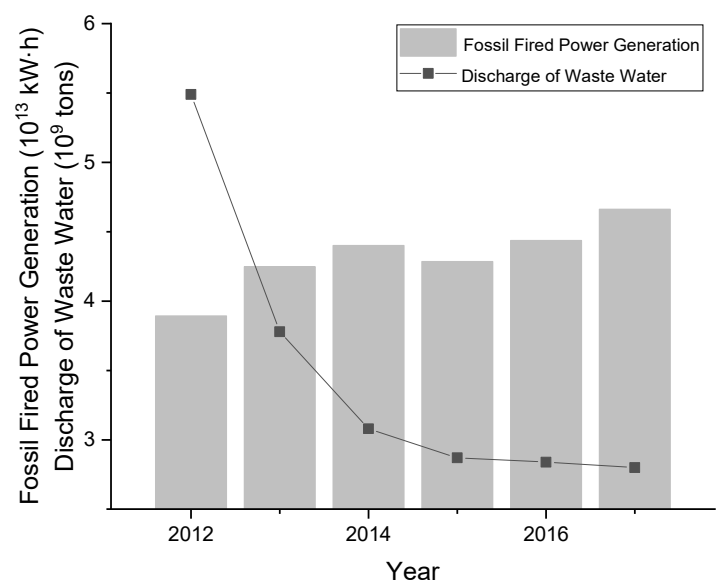

Fig 3. Changes of fossil fired power generation and the discharge of waste water in China (2012-2017)

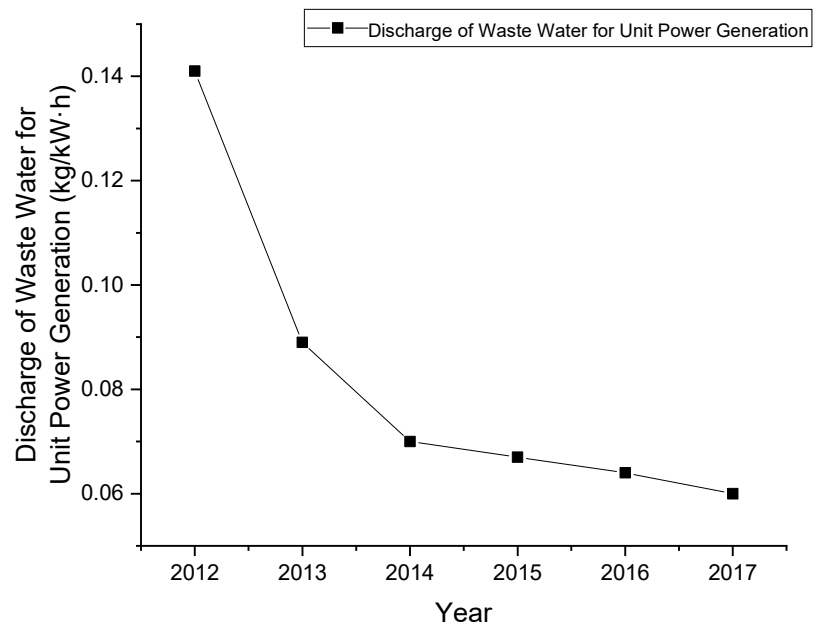

Fig 4. Discharge of waste water for unit power generation (2012-2017)

\section{Evaluation results}

Based on the evaluation on the implementation effect of the National Standard Norm of Water Intake-Part 1: Fossil Fired Power Production (GB/T18916.1-2012), it is obvious that the implement of the standard has promote the development of the industry from the three aspects. In terms of the technical aspect, first of all, the implementation of standard promoted the index reaching of backward production capacity. Secondly, the norm indexes were well in line with market development demands. Besides, the key technical indexes were not only consistent with the foreign industry development, but also consistent with relevant national, industry, local standards, and the requirements in relevant national documents. In terms of implementation, the standard and its derivative materials were well spread. After the publication, the standard has been training by the relevant department, also cited in scientific papers, and used in publicity materials and related books as derivative materials. On the other side, the standard was excellent adopted by the administrative sector, enterprises and the third-party institutions. Besides, the standard was quoted in many laws, regulations, national policy documents, and local standards. In terms of implementation benefits, after the implementation of the standard, the reduced quantity of water intake accounted for $10.07 \%$ of the annual water intake in the fossil fired power production, and the average discharge of waste water was reduced by $9.8 \%$. However, in terms of social benefits, there is no enterprise has participated in the relevant selection programs for water efficiency leaders and water saving enterprises, or the demonstrations and pilots of related water conservation standards.

According to the evaluation and analysis of the implementation effect of the National Standard Norm of Water Intake-Part 1: Fossil Fired Power Production (GB/T18916.1-2012), the implementation has achieved initial results in regulating the water intake and consumption in the fossil fired power production industry. The norm indexes in the standard shall be further revised based on the current industry development so as to promote the development of water conservation technologies in this industry. In addition, supervision shall 
be stepped up by establishing a real-time tracking mechanism for the implementation effect of the standard. Besides, the policy support, publicity efforts, and the selfregulation mechanisms of industry shall be strengthened in order to support the implementation of standard.

\section{Acknowledgments}

This work was supported by the National Key Research and Development Program of China (Grant No. 2017YFF0206701), and CNIS President's Fund supported project (Grant No. 542020Y-7456).

\section{References}

1. Wang Yuan, Sheng Lianxi, Li Ke, et al. Analysis of Present Situation of Water Resources and Countermeasures for Sustainable Development in China [J]. Journal of Water Resources and Water Engineering. 2008,19(3):10-14.

2. Cui Yansong. The Economics of Water Resources and the Theory, Policy and Use of Water Resources Management [M]. China Social Science Press, 2008.

3. Zhang Xifeng, Jin Xin, Bai Xiao, Jiang Yanbin, He Chansheng. Impacts of Water Resource Planning on Regional Water Consumption Pattern: A Case Study in Dunhuang Oasis, China [J].Journal of Arid Land,2019,11(05):713-728.

4. Zhang Weiguang, Chen Juan, Wang Hongrui, Fan Linlin, Cui Shengyu, Analysis of Water Consumption Quota Characteristics and Existing Problems [J]. South-to-North Water Transfers and Water Science and Technology, 2015,13(01):158-162.

5. State Council. Notice of the State Council on Issuing the Plan for Deepening the Reform of Standardization Work (GF [2015] No. 13) [EB/OL]. http://www.gov.cn/zhengce/content/201503/26/content_9557.htm, March 11, 2015.

6. Dong Chonglie. Analysis on Energy Conservation Transformation of Circulating Water System in Thermal Power Plant [J]. Information Recording Materials, 2018,19(09):29-31.

7. Xiang Haoxian. Problems and Technical Measures for Electrical Energy Saving and Consumption Reduction in Fossil fired power production Plants [J]. The Farmers Consultant, 2019(20):188.

8. Dai Min. Analysis of circulating water system in thermal power plant and energy saving technology of pump frequency conversion [J]. Engineering Technology:00092-00093.

9. GB/T18916.1-2012 Norm of Water Intake-Part 1: Fossil Fired Power Production[S].

10. Hu Mengting, Bai Xue, Cai Rong, Zhang Lijia, and Zhu Chunyan. A Study of the "Dual Control" Standard System for Total Water Consumption and Intensity[J]. Standard Science, 2019(08):69-74.

11. Beuth Verlag. Economic Benefits of Standardization: Summary of Results [R]. DIN German Institute for
Standardization, 2006:20-23.

12. Temple $\mathrm{P}$ et al. The Empirical Economics of Standards. The Department of Trade and Industry (DTI), Economics Paper NO. 12, 2005.

13. Wang Zhongmin. The Return of Britain - on the Empirical Economics of Standards [J]. Standard Science, 2005(12):25-28.

14. Blind $\mathrm{K}$ and E Jungmittag A. The Impact of Patents and Standards on Macroeconomic Growth: a Panel Approach Covering Four countries and 12 Sectors [J]. Journal of Productivity Analysis, 2008(29):51-60.

15. Blind $\mathrm{K}$ et al, The Economic Benefits of Standardization. An update of the study carried out by German Institute for Standardization (DIN) in 2000, 2011.

16. Li Jun, Wu Jie, Liu Yu. Literature Review and Analysis of the Domestic Research on Standard Implementation Effect Evaluation [J]. Standard Science, 2018(08):97-101.

17. Zhang Yubo, Bai Xue, Hu Mengting. Study on the Evaluation Index System for the Implementation Effect of Minimum Allowable Value of Water Efficiency and Water Efficiency Grades Standards [J]. Standard Science, 2020(01):10-13.

18. Gong Xianzheng, Zhou Liwei, Li Chengyang. Study on the evaluation of the implementation effect of energy consumption quota standard of cement unit product [J]. China Cement, 2019(08):116-121.

19. Ren Guanhua, Wei Hong, Liu Bisong, Zhan Junfeng. Study on the Applicability Evaluation System [J]. World Standardization and quality management, 2005(03):15-18.

20. Hu Mengting, Bai Xue, and Zhu Chunyan. A Study of the Methods to Evaluate the Implementation Effect of the Standard for the Norm of Water Intake[J]. China Standardization, 2018(17):52-56.

21. Li Yongzhi, Zhou Cheng et al. Study on Nation Standard of "Norm of Water Intake: Leather" [J]. Beijing Leather, 2020(06):21-25.

22. Ted L Napier. Soil and water conservation policy approaches in North America, Europe, and Australia [J]. Water Policy, 2000, 1 (6).

23. Sun Lian, Li Chunhui. Water Resource Management System of the World's Leading Country and Enlightenment to China [J]. Land and Resources Information | Land Resource Information, 2014(09):14-22.

24. Jiang Zisheng, Han Mailiang. Water Resources Utilization Situation and Countermeasures of Fossil fired power production Unit [J]. Huadian Technology, 2008(06):1-5.

25. Sang Lianhai, Zeng Xiang, Zhang Jin, and Feng Zhaoyang. Analysis of Water Intake Quantity and Quota of Fossil fired power production Industry in Yangtze River Basin [J]. Journal of Yangtze River Scientific Research Institute, 2014, 31(12):17-20.

26. He Shide, Zhang Zhanmei, and Zhou Yu. Progress in the Water Saving Technology in Fossil fired power 
production Plants [J]. Sichuan Electric Power Technology, 2008, 31(06):16-18+22.

27. GB/T26925-2011 Water Saving Enterprises-Fossil Fired Plant $[\mathrm{S}]$.

28. DL/T783-2018 Water Saving Guideline for Fossil fired power production Plant [S].

29. Pan Li, Liu Zhiqiang, Zhang Bo. Analysis and suggestions of water saving situation of thermal power in China [J]. China Power, 2017,50(11):158163.

30. DL/T606.5-2009 Guide for Energy Balance of Fossil fired power production Plant-Part 5: Water Balance Test $[\mathrm{S}]$.

31. Lu Qilun. Examples of Water Balance Testing and Water Saving Potential of Fossil fired power production Plants $[\mathrm{J}]$. Modern Business Trade Industry, 2011, 23 (14): 295-296.

32. Sun Ting, Zhang Yu, Shao Fang, and Han Yun. Theory and Application on Quota of Industrial Water Use in China [J]. China Water Resources, 2015(23):46-48.

33. GB/T 3533.1-2017 Standardization benefit evaluation-Part 1: General principles of economic benefit evaluation [S].

34. GB/T 3533.2-2017 Standardization benefit evaluation-Part 2: General principles of social benefit evaluation [S].

35. Jiao Jun. Application Research on Reasonable Assessment of the Fossil fired power production Industry Water Quota on Yellow River Basin [J]. Hefei University of Technology, 2015.

36. Annual Report on the Development of China's Power Industry [M]. China Market Press, 2018. 